ECCOMAS

Proceedia
COMPDYN 2019

$7^{\text {th }}$ ECCOMAS Thematic Conference on

Computational Methods in Structural Dynamics and Earthquake Engineering

M. Papadrakakis, M. Fragiadakis (eds.) Crete, Greece, 24-26 June 2019

\title{
EARTHQUAKE-INDUCED DAMAGE LOCALIZATION THROUGH NON-LINEAR DYNAMIC ANALYSIS
}

\author{
A. Kita ${ }^{1}$, N. Cavalagli ${ }^{1}$, M.G. Masciotta ${ }^{2}$, P.B. Lourenço ${ }^{2}$, and F. Ubertini ${ }^{1}$ \\ ${ }^{1}$ Department of Civil and Environmental Engineering, University of Perugia \\ Via G. Duranti, 93, 06125, Perugia, Italy \\ e-mail: \{alban.kita,nicola.cavalagli,filippo.ubertini\}@unipg.it \\ 2 ISISE, Department of Civil Engineering, University of Minho \\ Campus de Azurém, 4800-058, Guimarães, Portugal \\ e-mail: $\{$ mgm,pbl $\} @$ civil.uminho.pt
}

\begin{abstract}
The development of vibration-based long-term SHM methods for damage detection and preventive conservation of historic masonry buildings is receiving a growing trend of scientific interest. At the state of the art, well-acknowledged techniques for damage detection have been developed and validated, especially when dealing with earthquake-induced damages. The next scientific challenge to deal with in SHM is therefore damage localization, thus, not just detecting the occurrence of a damage, but also inferring, with a certain level of confidence, its location. This paper presents a methodology aimed at addressing the damage localization task in heritage masonry structures, based on Incremental Dynamic Analysis (IDA) carried out from a numerical model together with data recorded during the earthquake. IDA curves are built with reference to different portions of the structure, relating some local damage parameters (DMs) to some seismic or response intensity measures (IMs) and earthquake's intensity is used for locally identifying the damage in such portions. The choice of IM represents an important aspect of the IDA curves effectiveness and an appropriate study is carried out. The proposed methodology is validated through application to the numerical model of a reduced-scale masonry structure, called Brick House, which represents a well-known international benchmark case study tested on the LNEC-3D shaking table. The obtained results demonstrate that the proposed methodology is capable of achieving earthquake-induced damage detection and localization with a good level of approximation.
\end{abstract}

Keywords: Structural Health Monitoring, Damage localization, Incremental Dynamic Analysis, FE numerical modeling, Intensity measure, Damage measure. 


\section{INTRODUCTION}

Well-acknowledged data-driven techniques for earthquake-induced damage detection (EIDD) have been developed and validated in the scientific literature, within vibration-based long-term Structural Health Monitoring (SHM), aimed at preventive conservation of historic masonry buildings. Among them, data-driven damage detection methods using modal parameters as damage-sensitive features represent consolidated and validated techniques for EIDD in Cultural Heritage $(\mathrm{CH})$ masonry structures, even at stages when damage is not yet detectable by visual inspections $[1,2,3,4,5,6]$. Nevertheless, methods addressing higher levels of damage identification with a certain accuracy are yet to be defined. This paper seeks to tackle this challenge by presenting a numerical model-based methodology for earthquake-induced damage localization (EIDL) in masonry structures.

The proposed methodology is based on Incremental Dynamic Analysis (IDA) [7] combined with seismic data recorded via long-term vibration-based SHM. It requires the construction and tuning of a numerical model of the considered structure. In this regard, IDAs are carried out from a well calibrated numerical model, considering a suitable non-linear constitutive model for the masonry material, and relate a Damage Measure (DM) against one or more Intensity Measures (IMs). In the present work, each IDA curve is referred not to the whole structure but to some individual specific regions of the numerical model, called Parts, which it is ideally subdivided into. Hence, regional IDA curves can be used, for damage localization and quantification, through an appropriate IM of a seismic event. It can be either a seimic input IM (structure independent) or a structural response one (structure dependent). A particular focus has been dedicated to an in-depth study of all IMs existing in literature and, moreover, to the definition of new original ones, since the use of the most suitable IMs represents an important aspect in IDA's results and effectiveness. A statistical correlation study between IMs has been carried out, considering one hundred seismic records from the Italian Accelerometric Archive. Decisions on whether choosing some and discarding others have been made, taking also into account their capabilities to describe the main characteristics of an earthquake. Seismic input to non-linear dynamic analyses of structures is usually defined in terms of acceleration time series whose response spectra are compatible with a specified target response spectrum. For this purpose, the generation of seven accelerograms spectrum-compatible to the elastic response spectrum prescribed by the New Zealand Standards for the site of Christchurch city, has been described. The corresponding acceleration time histories are then appropriately scaled for IDA.

The proposed methodology is applied and validated through application to the Finite Element (FE) model of a well-known case study, named Brick House. It is a simple masonry structure, but an international scientific benchmark being tested on the LNEC-3D shaking table, whose obtained experimental results act as reference for calibration of the corresponding numerical model. The results demonstrate that the proposed numerical-based procedure is capable of correctly localizing earthquake-induced damage in different regions of the structure, and of quantifying it with a certain level of confidence.

The paper is organized as follows. Section 2 describes the proposed methodology for earthquakeinduced damage localization. Section 3 presents the considered case study, detailing both reference main experimental results and FE numerical modeling. Section 4 reports the results and validation of the proposed methodology and, finally, Section 5 summarizes the main conclusions that can be drawn from the work. 


\section{THE PROPOSED METHODOLOGY}

The proposed methodology, aimed at addressing the damage localization task in heritage masonry structures, is based on Incremental Dynamic Analysis (IDA) carried out from a well calibrated numerical model together with data recorded during the earthquake.

IDA represents a parametric analysis method capable of thoroughly estimating structural performance under dynamic and seismic loads [7]. It involves subjecting the FE model to one (or more) ground motion record(s), each scaled to multiple levels of intensity, thus producing one (or more) curve(s) of response parameterized versus the intensity level. An IDA study allows a thorough understanding of the range of response or 'demands' versus the range of potential levels of a ground motion record, as well as, a better understanding of the structural response/implications as the ground motion intensity increases to more severe levels. Moreover, in the framework of performance-based earthquake engineering (PBEE), the assessment of demand and (global collapse) capacity is viewed through the lens of an IDA study. The IDA curve contains the necessary information to assess performance levels or limit states. Indeed, different levels of capacity can be associated to different limit states.

Basic hierarchical concepts of Incremental Dynamic Analysis are listed below:

- Unscaled single acceleration time-history: $\mathbf{a}_{1}$, defined as a vector $\mathbf{a}_{1}\left(t_{i}\right), t_{i}=0, t_{1}, \ldots, t_{n-1}$.

- Scale Factor (SF) of a scaled accelerogram: $\lambda \in[0,+\infty)$ that produces $\mathbf{a}_{\lambda}=\lambda \cdot \mathbf{a}_{1}$.

- Monotonic Scalable Intensiy Measure (IM): non-negative scalar IM $\in[0,+\infty)$ that constitutes a function of the scaled accelerogram $\mathbf{a}_{\lambda}, \mathrm{IM}=f_{\mathbf{a}_{1}}(\lambda)$.

- Damage Measure (DM): non-negative scalar DM $\in[0,+\infty)$ representing the output of the corresponding non-linear dynamic analysis on the structural model.

- Single-Record IDA Study: a dynamic analysis study of a given structural model parameterized by the SF applied to $\mathbf{a}_{1}\left(t_{i}\right)$, thus, involving a series of dynamic non-linear runs performed under scaled images of $\mathbf{a}_{1}\left(t_{i}\right)$.

- IDA Curve: plot of a DM recorded in an IDA study versus one or more IMs that characterize $\mathbf{a}_{\lambda}$ (+2D plot).

A Single-Record IDA Study is accelerogram and structural model specific. When subjected to different ground motions, a model will often produce quite dissimilar responses that are difficult to predict a priori, being not able to fully capture the behaviour that a building may display in a future event. In other words, it can be highly dependent on the chosen record, so a sufficient number of records is needed to cover the full range of responses. Hence, the structural model has to be subjected to a suite of ground motion records.

- Multi-Record IDA Study: a collection of single-record IDA studies of the same structural model, under different accelerograms.

- IDA Curve Set: a collection of IDA curves of the same structural model under different accelerograms, that are all parameterized with respect to the same IMs and DM.

A detailed overview of the aforementiond basic concepts can be found in[7].

The methodology proposes IDA curves generated with reference to individual different portions of the structure (and not the whole structure), relating some local damage parameters 
(DMs) to selected seismic or response intensity measures (IMs). Seismic input and/or numerical response intensities (IMs) can be used in such curves for local identification and quantification of damage (DM) in each portion. A Single-Record IDA Study results into an IDA Curve which constitutes a mathematical entity, relating one or more DMs to one or more IMs:

$$
\underline{\mathrm{DM}}=f(\underline{\mathbf{I M}})
$$

where $\underline{\mathrm{DM}}=\left(\mathrm{DM}_{1}, \mathrm{DM}_{2}, \ldots, \mathrm{DM}_{\mathrm{n}}\right)$ and $\underline{\mathrm{IMs}}=\left(\mathrm{IM}_{1}, \mathrm{IM}_{2}, \ldots, \mathrm{IM}_{\mathrm{m}}\right)$ with $\mathrm{n}$ referred to $\mathrm{n}$ different regions of the numerical model and $\mathrm{m}$ the total number of best IMs considered. Assuming monotonic IMs, the IDA curve in (Eq. (1)) becomes a function $\left(R^{* m} \rightarrow R^{* n}\right.$ ), being $R^{*}$ the set of non-negative real numbers. Relationship between $\underline{\mathrm{DM}}$ and IMs is multidimensional, whereby, the results of an IDA study, expressed by Eq. (1), can be presented in a multitude of different IDA curves, depending on the choices of IMs. Such a choice represents an important aspect of the IDA curves effectiveness, hence an appropriate study is carried out in Section 4.1. Moreover, given the dependence of IDA on the chosen record and taking into account the variability of structural responses with respect to different ground motions a suite of ground motion records has been considered. At least seven seismic records should be considered, as suggested by technical standards [8], aimed at covering full range of responses, different seismic characteristics in terms of energy, frequency content and more.

The scheme of the proposed methodology is illustrated in Fig. 1.
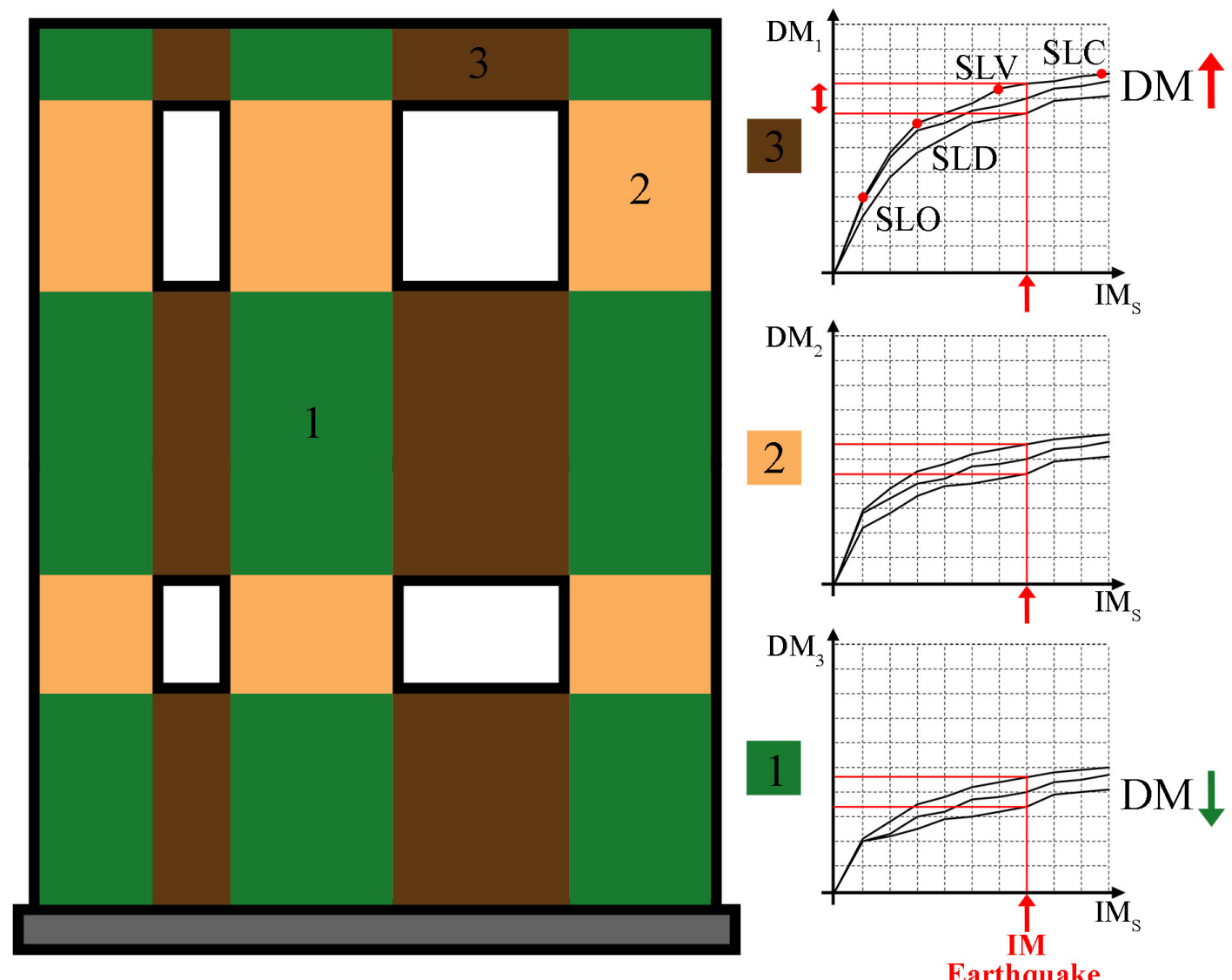

Figure 1: Scheme of the proposed methodology. 


\section{BRICK HOUSE}

\subsection{Experimental model}

As introduced before, the IDA methodology has been validated through the numerical simulation of the Brick House, whose experimental conterpart was tested in the LNEC-3D shaking table. The tests, carried out in the scope of the workshop "Methods and Challenges on the Out-of-Plane Assessment of Existing Masonry Buildings" [9], aimed at the assessment of its out-of-plane performance under dynamic and seismic loading.

The Brick House mock-up was built using regular fired clay bricks with an English bond masonry arrangement, yielding a total wall thickness of around $23.5 \mathrm{~cm}$. It presented three walls set out according to a $U$ shape layout: the façade wall with a central opening and a gable on top and the two orthogonal sidewalls, acting as abutments, of which only one was pierced by a window.

Unidirectional seismic loading, in the perpendicular direction to the façade, was applied with increasing input intensity testing protocol up to collapse. The pre-processed N64E strong ground motion component of the Christchurch (New Zealand) earthquake of February $21^{\text {st }} 2011$ was used. In this way, the façade was loaded in the out-of-plane direction, while the sidewalls were loaded in-plane but, given the presence of a window in one of the sidewalls, an asymmetric dynamic behavior was observed, leading to significant torsion of the structure. The seismic test sequence included eight steps of increasing intensity, where the last one reached an amplitude of about $12.47 \mathrm{~m} / \mathrm{s}^{2}$. The collapse mechanism observed at the end presented partial collapse of the gable top of the façade and of the lateral wall with window, while the other sidewall remained almost intact (see Figs. 2a, b, c). The instrumentation included twenty unidirectional accelerometers and six linear variable displacement transducers (LVDTs), placed in different locations for measuring the absolute acceleration responses of the structure, as well as the input signals on the shake table, and the out-of-plane displacements of the façade, respectively.

Further details on the description of the mock-up, seismic testing, instrumentation setup, damage pattern and observed collapse mechanisms are presented in [10].

\subsection{Construction and validation of FE numerical model}

In order to simulate earthquake-induced damage scenarios and carry out IDA aimed at damage localization, a 3D FE model of the Brick House mock-up has been built using the ABAQUS 6.10 platform [11] (see Fig. 3a). A free meshing of solid tetrahedral elements, with mean elements' dimension of about $10 \mathrm{~cm}$, has been adopted. The choice of such a mesh dimension was

(a)

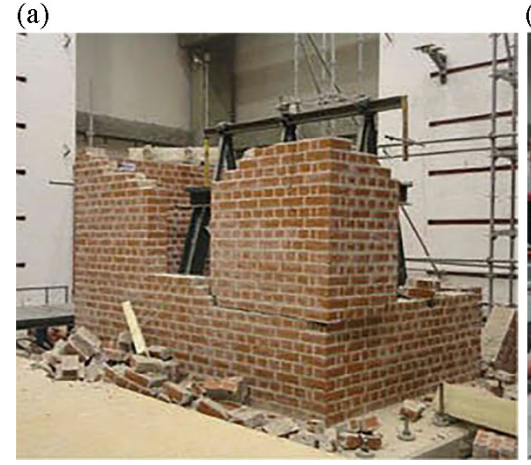

(b)

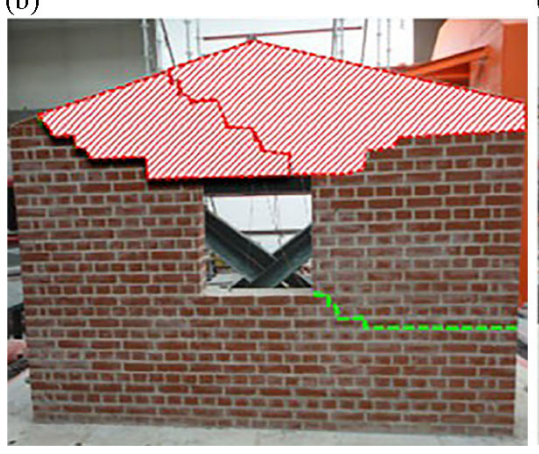

(c)

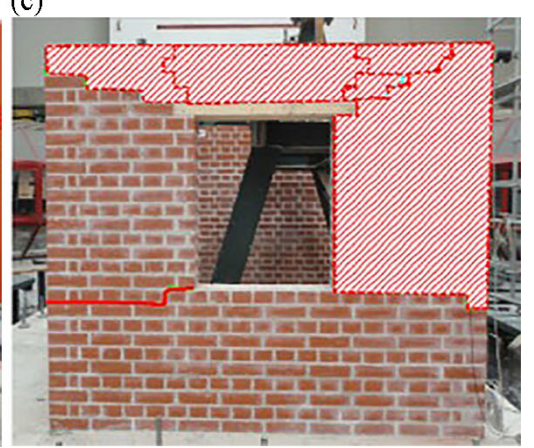

Figure 2: Brick masonry prototype after shaking table test (a) and collapse mechanism scheme with particular view on the main gable wall (b) and return wall with window opening (c) [10]. 
(a)

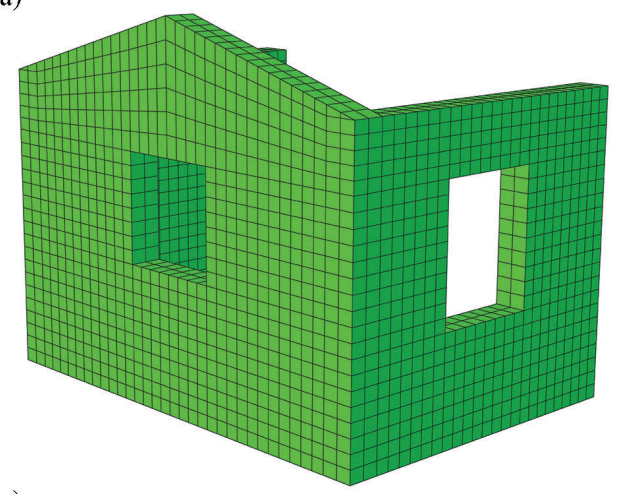

(c)

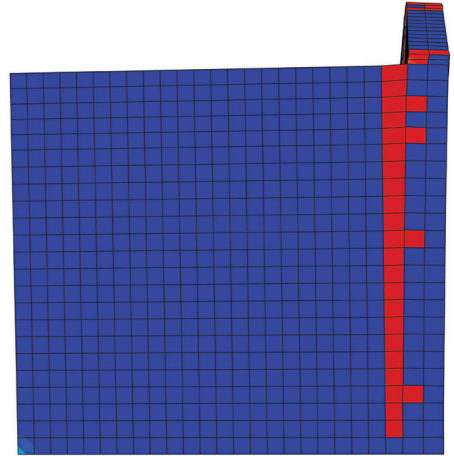

(b)

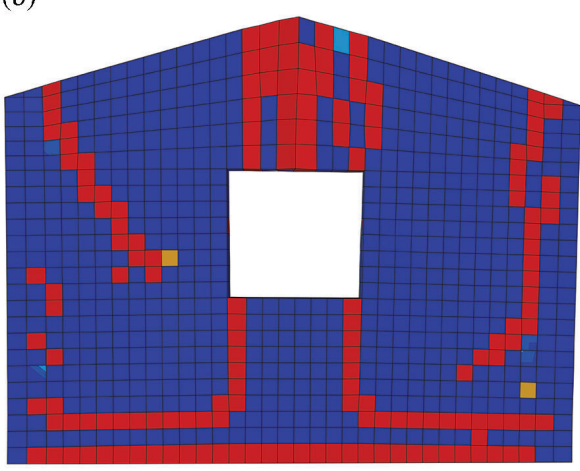

(d)

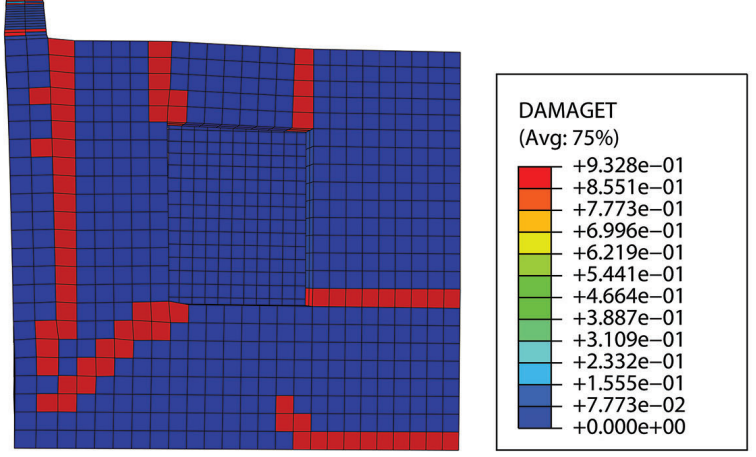

Figure 3: Brick House numerical model: mesh discretization view (a) and damage obtained after Christchurch earthquake simulation in the main gable wall (b) and in the return walls without (c) and with window opening (d).

the result of a preliminary sensitivity analysis, not reported here for the sake of brevity, looking for a trade-off between accuracy of the solution and control of computational costs. The model has been assumed fixed to the ground. At the constitutive level, the same material has been assigned to the whole structure assuming an isotropic behavior.

Linear mechanical parameters of the masonry can be found in [10], as estimated after characterization in-situ experimental tests on six wallets. The non-linear mechanical behavior has been here reproduced, as suggested in recent literature works on seismic vulnerability analysis [12], using the classic Concrete Damaged Plasticity (CDP) constitutive model proposed by Lubliner and co-workers [13] and then modified by Lee and Fenves [14] for cyclic loading and damage implementation. CDP is a continuum, plasticity-based model for quasi brittle materials with nonlinear behavior in tension (tensile cracking) and compression (crushing), but elastic in shear. In the case of the Brick House mock-up, despite the absence of data to accurately describe the non-linear behavior in tension and the failure of experimental in-situ diagonal compression tests, the post-elastic material response (with reference to the mortar) in tension and compression (assumed to be exponentially decreasing) is suggested in [15].

In the present numerical model, the aforementioned linear and non-linear parameters resulted crucial for the calibration process. However, it should be emphasized that, for obtaining full consistency between numerically predicted and experimentally recorded response accelerations, an additional manual tuning was needed. The following linear parameters are adopted: Young's modulus $E$, Poisson's ratio $\nu$, specific weight $\gamma$ and tensile and compressive strength $\left(\sigma_{t}\right.$ and $\left.\sigma_{c}\right)$ as reported in Tab. 1. Regarding CDP, with reference to the suggested values, slightly different but reasonable damage parameters in tension are adopted (see Tab. 2). The description of the failure condition and of the post-peak behavior depends upon the tensile stresses, $\sigma_{t}$, the 


\begin{tabular}{ccccc}
\hline $\begin{array}{c}E \\
{\left[\mathrm{kN} / \mathrm{m}^{2}\right]}\end{array}$ & $\begin{array}{c}\nu \\
{[-]}\end{array}$ & $\begin{array}{c}\gamma \\
{\left[\mathrm{kN} / \mathrm{m}^{3}\right]}\end{array}$ & $\begin{array}{c}\sigma_{t} \\
{\left[\mathrm{kN} / \mathrm{m}^{2}\right]}\end{array}$ & $\begin{array}{c}\sigma_{c} \\
{\left[\mathrm{kN} / \mathrm{m}^{2}\right]}\end{array}$ \\
\hline $3.619 \mathrm{E}+06$ & 0.3 & 18.9 & 252 & 2480 \\
\hline
\end{tabular}

Table 1: Mechanical parameters adopted on Brick House FE numerical model.

cracking strains, $\tilde{\varepsilon}_{t}^{c k}$, and the tensile damage variable, $d_{t}$. In this regard, the behavior of the masonry has been reproduced up to the ultimate limit state, considering damage in tension only.

The validation of the Brick House FE model has been performed by investigating its damage pattern predicted after Chritchurch earthquake numerical simulation (using the same input motion of the experimental tests), as illustrated in Figs. 3b, c, d, with reference to experimental collapse mechanism observed in the shaking table test. Furthermore, numerically predicted and experimentally measured response accelerations are compared in five strategic and meaningful reference points (see Fig. 4). As per displayed plots, the model can be considered well validated, hence ready for Incremental Dynamic Analysis.

\begin{tabular}{ccc}
\hline $\begin{array}{c}\sigma_{t} \\
{\left[\mathrm{kN} / \mathrm{m}^{2}\right]}\end{array}$ & $\begin{array}{c}\tilde{\varepsilon}_{t}^{c k} \\
{[-]}\end{array}$ & $\begin{array}{c}d_{t} \\
{[-]}\end{array}$ \\
\hline 252 & $0.0 \mathrm{E}-00$ & 0.00 \\
198 & $3.0 \mathrm{E}-05$ & 0.20 \\
99 & $8.0 \mathrm{E}-05$ & 0.40 \\
45 & $1.1 \mathrm{E}-04$ & 0.70 \\
22 & $1.8 \mathrm{E}-04$ & 0.90 \\
\hline
\end{tabular}

Table 2: Mechanical parameters of tension stiffening and tension damage assumed in the numerical model.

\section{INCREMENTAL DYNAMIC ANALYSIS CURVE SETS}

\subsection{Intensiy measures IMs and Damage Measures DMs}

One of the most important aspects of a Single-Record IDA Study concerns definition and choice of a Ground Motion Intensiy Measure, or simply called IM. The results of an IDA study, expressed by Eq. (1), can be presented in a multitude of different IDA curves, depending on the used DM and IMs.

In order to thoroughly describe an earthquake, an IM should be able to describe three main characteristics/features of the ground motion that are of engineering significance such as, amplitude, frequency content and duration. The most common IMs describing amplitude are Peak Ground Acceleration (PGA), Peak Ground Velocity (PGV), Peak Ground Displacement (PGD). Other measures of amplitude include Sustained Maximum Acceleration (SMA) and Effective Design Acceleration (EDA). Secondly, it is well known that the dynamic response of compliant objects, be they buildings, bridges, slopes, or soil deposits, is very sensitive to the frequency at which they are loaded. The frequency content describes how the amplitude of a ground motion is distributed among different frequencies. Since the frequency content of an earthquake motion strongly influences the effects of that motion itself, characterization of the motion cannot be complete without consideration of its frequency content. In this regard, spectral parameters 

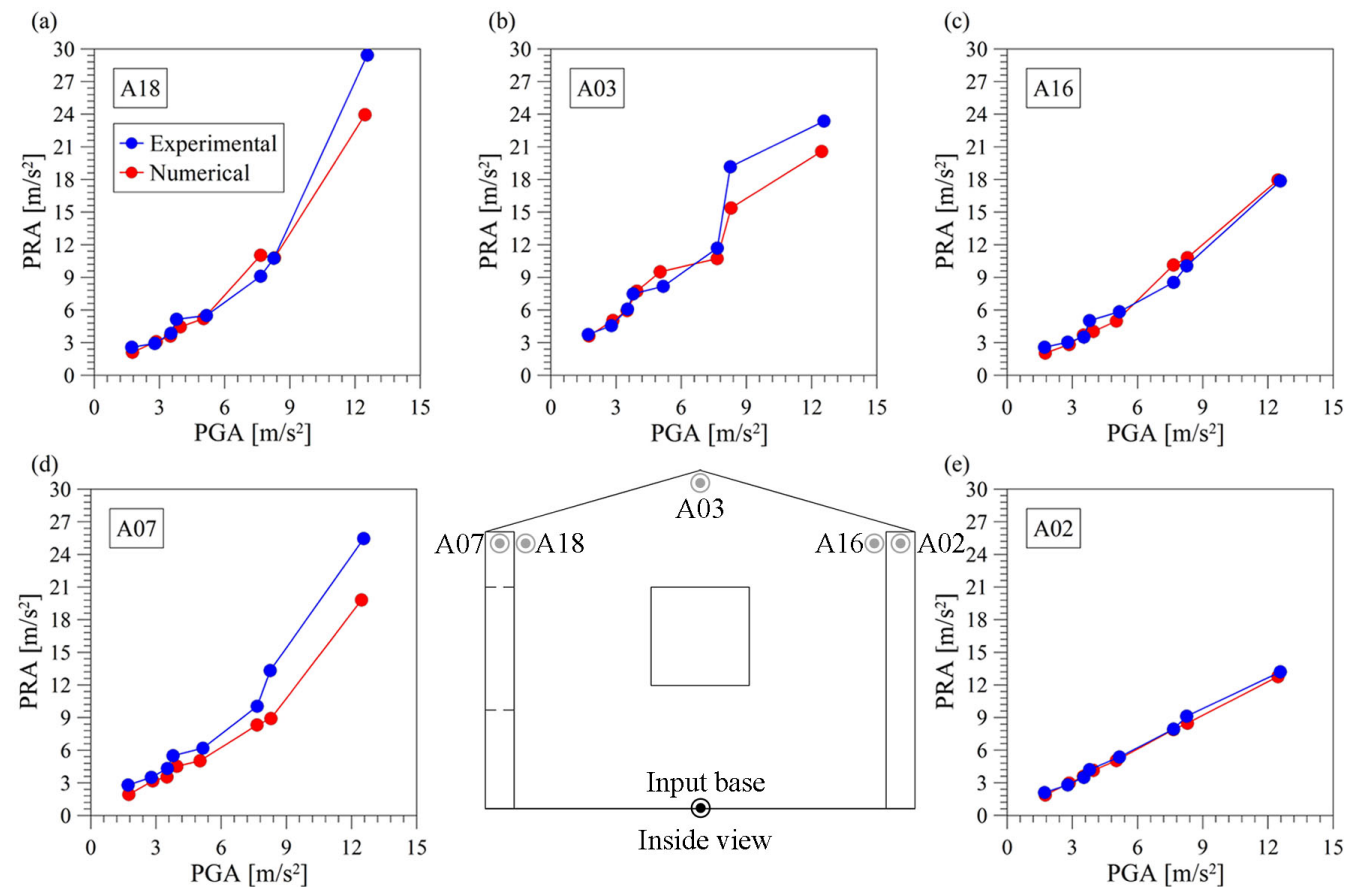

Figure 4: Experimental accelerometers layout and plots of numerical predicted response accelerations versus shaking table experimental ones with reference to five measuring points: A07, A18, A03, A16 and A02.

are suitable IMs. The duration of an earthquake (time interval where the strong ground motion results significative) is also a very important parameter because it influences the amount of damage due to earthquake. Experience has confirmed that a very high amplitude strong motion of short duration may not cause as much damage to a structure as a moderate motion with long duration can cause. This is because the ground motion with long duration causes more load reversals, aspect of utmost importance in terms of structural stiffness degradation. Moreover, all the integral measures depend upon the duration of the earthquake. Among many definitions of earthquake's duration, the main ones are represented by the total, uniform, bracketed and significant duration. The latter is used for integral IMs computation.

It is noteworthy to stress that identifying a reasonable number of IMs, that reflect the aforementioned characteristics of the ground motion, results of particular importance for IDA's effectiveness. For this purpose, an in-depth research and study have been carried out. A relatively large number of different IMs have been proposed in the literature, each of them providing information about one or more of these characteristics. In practice, it is usually necessary to use more than one IMs to characterize a particular ground motion adequately. Original definitions of IMs can be also provided, particularly as far as numerical-based response IMs are concerned, however, it is not the focus of this work.

Intensity measures can be subdivided in several categories or groups. They can be computed as peak or integral parameters. Also, they are considered as either seismic input measures (computed from the ground motion record, hence structure independent) or response intensity measure (structure dependent). With reference to modal properties of a structure, IMs are categorized in acceleration-related, velocity-related, displacement-related and mixed or hybrid [16]. For the sake of brevity and considering the Brick House dyanmic properties, only accelerationrelated IMs are reported in this work (see Tab. 3). The first four represent seismic peak IMs, the subsequent seven (5 to 11) are seismic integral IMs and the remaining quantities represent response peak IMs (12 to 16) and response integral IMs (17 to 20). 


\begin{tabular}{lllc}
\hline No. & Name & Notation & Ref. \\
\hline 1 & Peak Ground Acceleration & PGA & {$[16]$} \\
2 & Sustained Maximum Acceleration & SMA & {$[17]$} \\
3 & Effective Design Acceleration & EDA & {$[18]$} \\
4 & Riddell\&Garcia index & $\mathrm{I}_{\mathrm{a}}$ & {$[19]$} \\
5 & Root mean square Acceleration & $\mathrm{RMSA}$ & {$[16]$} \\
6 & Characteristic intensity & $\mathrm{I}_{\mathrm{C}}$ & {$[20]$} \\
7 & Arias Intensity & $\mathrm{I}_{\mathrm{A}}$ & {$[21]$} \\
8 & Acceleration parameter & $\mathrm{A}_{95}$ & {$[22]$} \\
9 & Destructive Potential Factor & $\mathrm{P}_{\mathrm{D}}$ & {$[23]$} \\
10 & Cumulative Absolute Velocity & $\mathrm{CAV}$ & {$[24]$} \\
11 & Maximum Incremental Velocity & $\mathrm{MIV}$ & {$[25]$} \\
12 & Peak Response Acceleration & $\mathrm{PRA}$ & {$[-]$} \\
13 & Spectral acceleration & $\mathrm{S}_{\mathrm{a}}(\mathrm{T} 1)$ & {$[26]$} \\
14 & Effective Peak Acceleration & $\mathrm{EPA}$ & {$[25]$} \\
15 & Inelastic behaviour spectral acceleration & $\mathrm{S}_{\mathrm{paC}}$ & {$[27]$} \\
16 & The geometric mean of spectral acceleration & $\mathrm{S}_{\mathrm{a}, \mathrm{avg}}$ & {$[28]$} \\
17 & Integral Response Acceleration & $\mathrm{IRA}$ & {$[-]$} \\
18 & Von Thun P-Acceleration Spectrum Intensity & $\mathrm{ASI}_{\mathrm{VT}}$ & {$[29]$} \\
19 & Modified P-Acceleration Spectrum Intensity & $\mathrm{ASI}_{\mathrm{MOD}}$ & {$[29]$} \\
20 & Nau\&Hall P-Acceleration Spectrum Intensity & $\mathrm{ASI}_{\mathrm{NH}}$ & {$[30]$} \\
\hline
\end{tabular}

Table 3: Acceleration-related intensity measures.

With a complete overview on many IMs, a statistical correlation study between them is carried out, aimed at understanding the most suitable and meaningful ones for IDA purposes. To this end, fifty earthquakes with moment magnitude higher than $\mathrm{M}_{\mathrm{w}}=5$ have been selected from the ITACA (ITalian ACcelerometric Archive) strong motion database [31, 32], taking into consideration normal, thrust and strike-slip faulting mechanisms. One near-field and one far-field record have been considered for each earthquake, thus having a total of one hundred seismic records. It is noteworthy to stress that input acceleration, velocity and displacement time histories are given in East and North directions, but for simplicity, IMs are computed considering their mean direction. Coefficients of determination $R^{2}$ between only accelerationrelated IMs, as computed from the said one hundred seismic records, are taken into account. In general, there is a high degree of correlation. As a consequence, between two highly correlated IMs (e.g. $R^{2} \geq 0.9$ ), only the one describing better the ground motion characteristics is selected. Therefore, the following 7 IMs are considered in this work for IDA curves: PGA, $I_{C}, I_{A}, P_{D}$, $\mathrm{CAV}, \mathrm{S}_{\mathrm{a}}(\mathrm{T} 1)$ and $\mathrm{ASI} \mathrm{MOD}_{\mathrm{D}}$. The latter is a variant of $\mathrm{ASI}_{\mathrm{VT}}$ with respect to the Brick House modes of vibration.

The DMs used in the present case study are represented by output variables obtained from Abaqus numerical model, namely: tensile damage parameter, $d_{t}$, plastic strain magnitude, $P E M A G$, and maximum principal plastic strain, PEP1. For damage localization purposes, the Brick House FE model has been partitioned into nine portions, viz. Parts (see Fig. 5), thus allowing a local estimation of DMs, which are computed as average values weighted on the numerical elements' volumes, within each single Part of the FE model. 


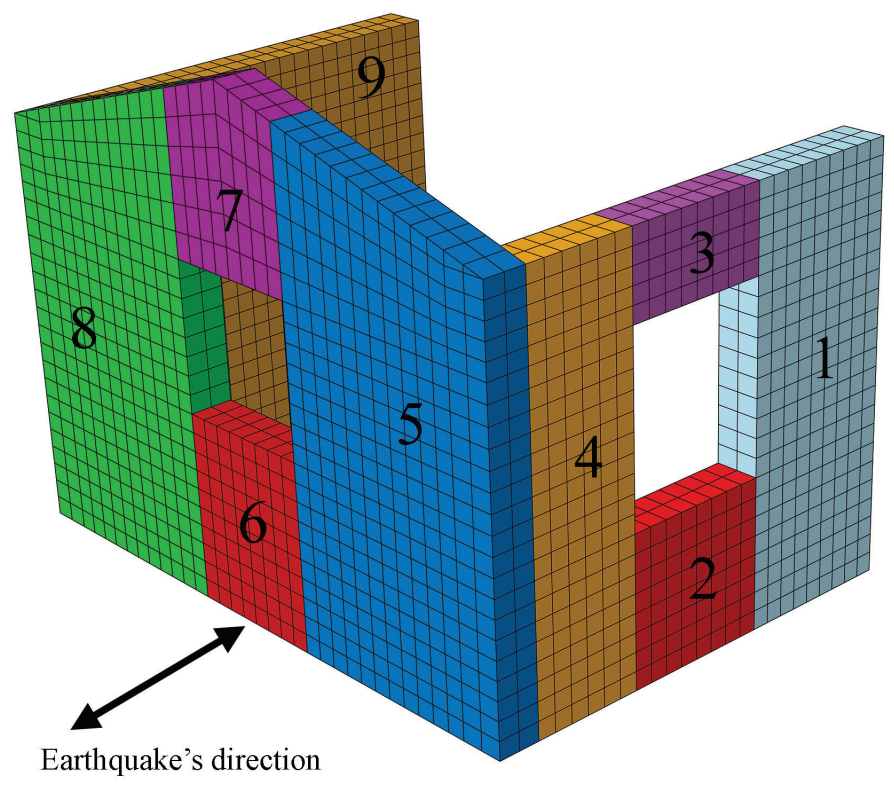

Figure 5: Nine portions of the Brick House numerical model considered for IDA.

\subsection{IDA Curve Sets}

The proposed methodology considers, for each region of the structure, a Multi-Record IDA Study whose output is an IDA Curve Set. In fact, given the dependence of a Single-Record IDA Study on the chosen record and taking into account the variability of structural responses with respect to different ground motions, a suite of ground motion records has been considered, aimed at covering different seismic characteristics in terms of duration, amplitude, energy, frequency content etc, as well as, having a higher probability of capturing several possible damage mechanisms. Seismic input to non-linear dynamic analyses of structures is usually defined in terms of acceleration time series whose response spectra are compatible with a specified target response spectrum. Previous works give an insightful description of the rationale and advantages in the use of spectrum-matched accelerograms [33], and demonstrate that spectrum matching does not lead to significant bias in structural analysis results [34].

In the present case study, seven ground motion accelerograms, whose main original informations are syntethized in Tab. 4, are matched to the elastic response spectrum prescribed by the New Zeland Standards NZS 1170.5:2004 [35, 36] at the site of Christchurch city, assuming Hazard Factor $Z=0.3$ (updated after Christchurch earthquake [37]), Return Period Factor $(\mathrm{Rs} / \mathrm{Ru})=1$, D subsoil category and $2.5 \mathrm{~km}$ distance to the nearest major fault. The spectrum compatibility has been realized by SeismoMatch [38], an application capable of adjusting real earthquake accelerograms to match a specific target response spectrum (spectrum matching) by adding wavelets to the original time history of acceleration (wavelet addition in the time domain). Realistic acceleration time series are generated by modifying existing accelerograms while preserving the nonstationary character of the ground motion. Time histories of (unscaled) spectrum-matched accelerations $\mathbf{a}_{1}$ are illustrated in Figs. 6a-g. Applied as unidirectional seismic loading, in the perpendicular direction to the façade, they are scaled up with increasing intensity by means of SFs $\left(\lambda, \mathbf{a}_{\lambda}=\lambda \cdot \mathbf{a}_{1}\right)$ equal to $1,1.5,2,2.5, \ldots, 5$.

With reference to the nine Parts, IDA Curve Sets (Eq. (1)) relate the selected local DMs to the chosen seismic or response IMs. For the sake of brevity, only IDA Curve Sets obtained from tensile damage and plastic strain magnitude versus the corresponding best acceleration-related 

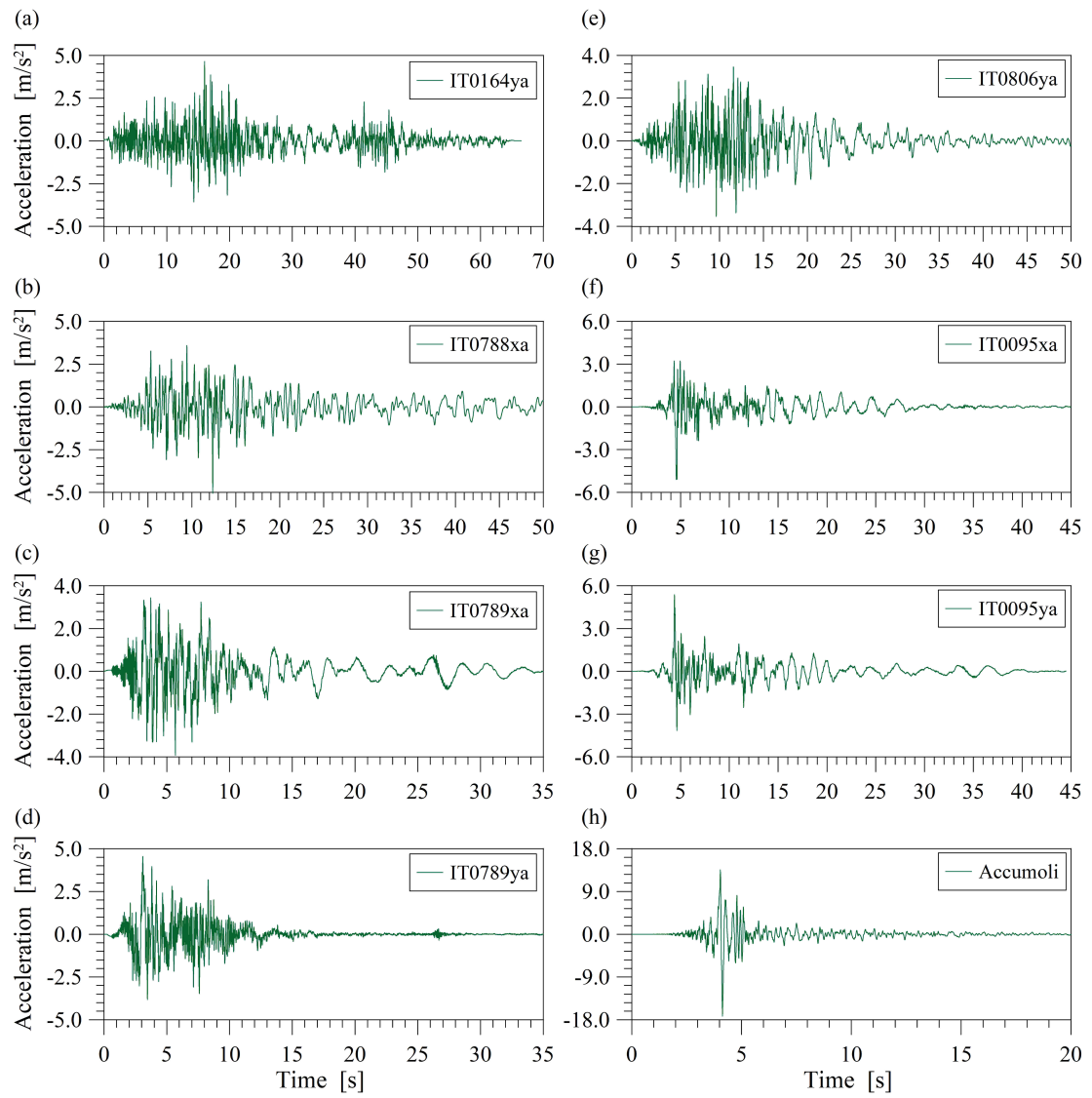

Figure 6: Plot of unscaled acceleration time histories used for Incremental Dynamic Analysis on Brick House FE model ((a)-(g)) and scaled (SF=2) East-West component of Accumoli Mw6.0 earthquake of August 24th 2016 (h).

\begin{tabular}{ccccccc}
\hline $\begin{array}{c}\text { Earthquake ID } \\
{[-]}\end{array}$ & $\begin{array}{c}\text { Station ID } \\
{[-]}\end{array}$ & $\begin{array}{c}\text { Epicenter } \\
{[-]}\end{array}$ & $\begin{array}{c}\text { Date } \\
{[\mathrm{dd} / \mathrm{mm} / \mathrm{yyyy}]}\end{array}$ & $\begin{array}{c}\text { Mw } \\
{[-]}\end{array}$ & $\begin{array}{c}\text { Fault } \\
{[-]}\end{array}$ & $\begin{array}{c}\text { PGA } \\
{\left[\mathrm{m} / \mathrm{s}^{2}\right]}\end{array}$ \\
\hline IT0164ya & ALT & Irpinia & $23 / 11 / 1980$ & 6.9 & Normal & 4.645 \\
IT0788xa & ANT & L'Aquila & $06 / 04 / 2009$ & 6.3 & Normal & 5.057 \\
IT0789xa & AQA & L'Aquila & $06 / 04 / 2009$ & 6.3 & Normal & 3.931 \\
IT0789ya & AQA & L'Aquila & $06 / 04 / 2009$ & 6.3 & Normal & 4.550 \\
IT0806ya & FMG & L'Aquila & $06 / 04 / 2009$ & 6.3 & Normal & 3.532 \\
IT0095xa & NRC & Ussita & $26 / 10 / 2016$ & 5.9 & Normal & 5.101 \\
IT0095ya & NRC & Ussita & $26 / 10 / 2016$ & 5.9 & Normal & 5.371 \\
\hline
\end{tabular}

Table 4: Ground motions used for Incremental Dynamic Analysis on the Brick House FE model: PGAs refer to spectrum-matched time histories.

IM, in terms of dispersion, are presented in this work. Fig. 7 shows the nine plots of dt versus $\mathrm{ASI}_{\mathrm{MOD}}$ (simply called ASI from here on), whereas the nine plots of PEMAG versus $\mathrm{I}_{\mathrm{A}}$ are shown in Fig. 8. In addition to the set of curves, mean curves are depicted in the first graphs with a thick black line.

By investigating these plots, it is possible identifying the least and most vulnerable parts of the Brick House numerical model. In the case of dt, Figs. 7a, i indicate that Parts 1 and 9 are the least damaged regions, with corresponding reached maximum values of tensile damage equal to about 0.4 (40\% reduction of Young's modulus). Indeed, by examining Figs. 7d, e, g, h it is clear that the most vulnerable/damaged parts are 4, 5, 7 and 8 , with maximum tensile damage equal 
(a)

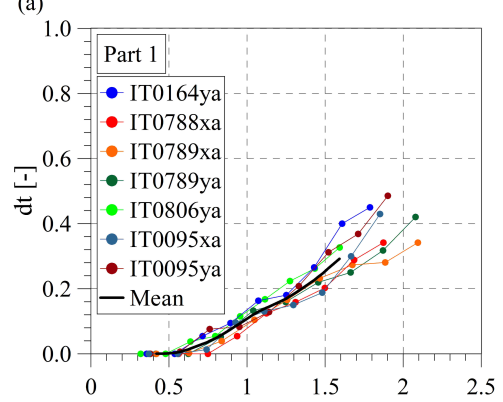

(d)

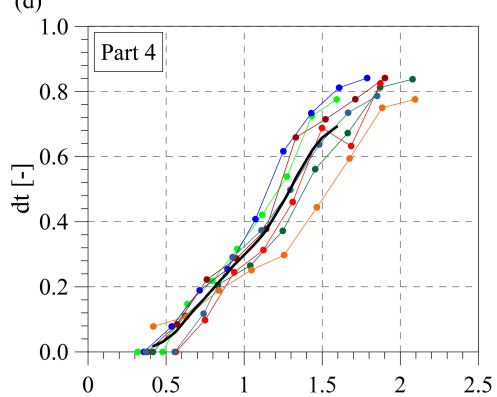

(g)

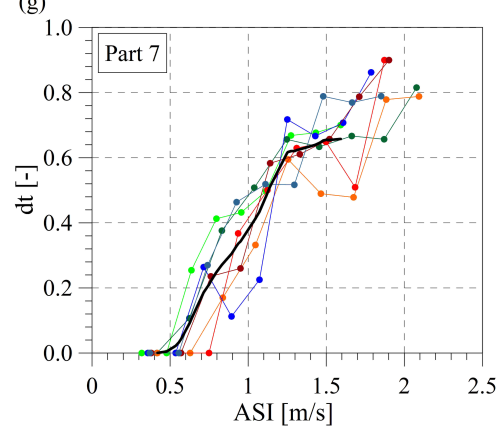

(b)

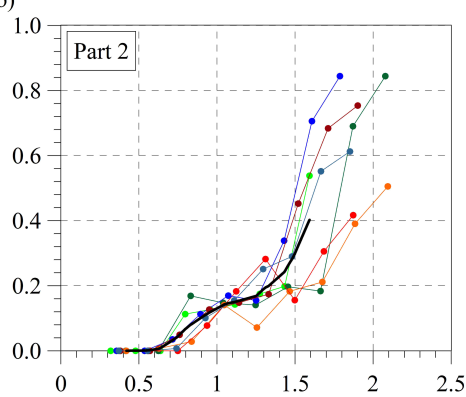

(e)

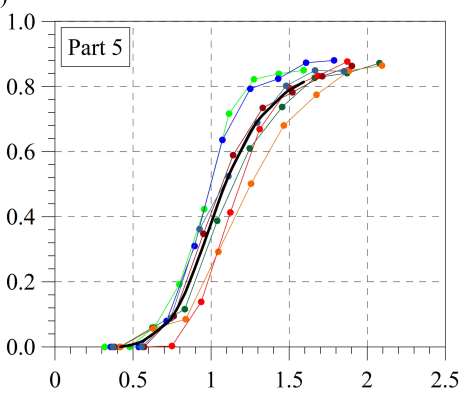

(h)

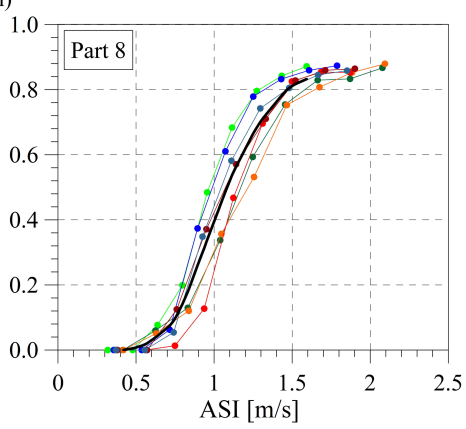

(c)

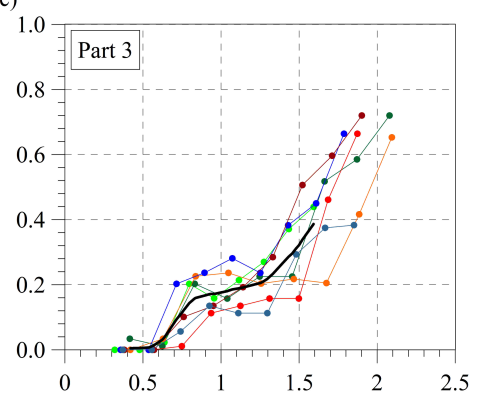

(f)

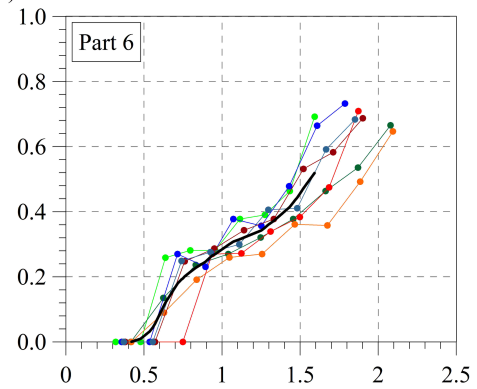

(i)

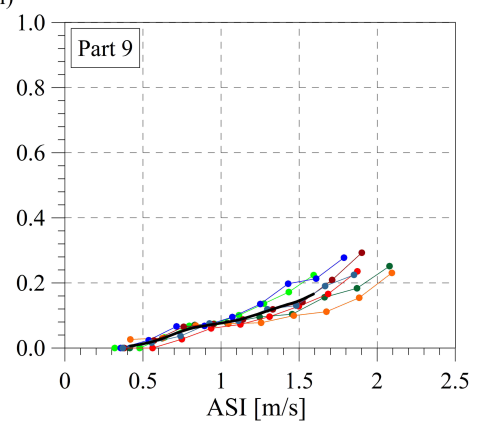

Figure 7: IDA Curve Sets and corresponding mean curves: plots of tensile damage $d_{t}$ versus Acceleration Spectrum Intensity ASI.

nearly to 0.9 , being this the maximum value predicted by CDP consitutive model (meaning $10 \%$ stiffness residue in tension). Part 7 seems to be the first region damaged over time with increasing seismic intensity, followed by Parts 5,8 and 4. All these observations are in good agreement with the damaging process and pattern observed in experimental tests (see Fig. 2). It is noteworthy to stress that tensile damage represents a parameter which takes into account the history of damage. It is a measure of the plastic flow. Considering the unidirectional seismic loading, Parts 5 and 8 , as parts of the façade wall with out-of-plane loading, present a high level of damage even because they suffer due to the presence of the two orthogonal sidewalls, acting as abutments. On the other hand, PEMAG represents a measure of tensile deformation, which in the present case study, is strongly related to formation and development/opening of crack. Plots in Fig. 8 show that PEMAG presents its highest values in Parts 7 and 4, which correspond, respectively, to the top gable and the adjacent region of the sidewall with opening.

For a better understanding of the damage pattern obtained via IDA, Fig. 9 shows contour plots of dt and PEMAG at the last step of the non-linear dynamic analysis carried out with IT0806ya earthquake scaled at $\mathrm{SF}=3.5$. Tensile damage is clearly predominant in Parts $7,5,8$ and 4, whereas plastic strain magnitude is concentrated in Part 7 and 4. Overall, the observed experimental crack formation and collapse mechanism/damage pattern [10] are confirmed by IDA Curve Sets, considering both dt and PEMAG. 

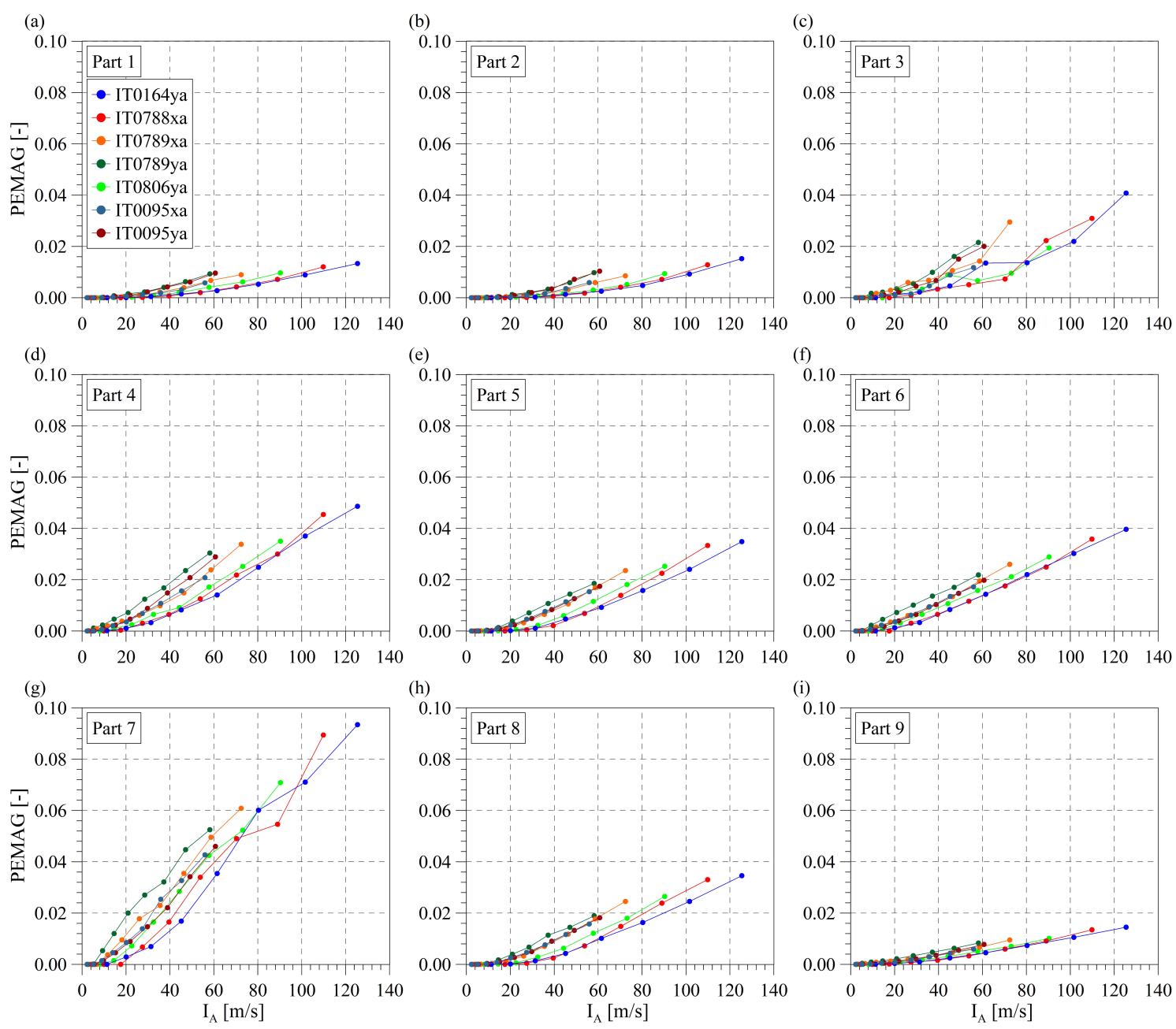

Figure 8: IDA Curve Sets: plots of plastic strain magnitude PEMAG versus Arias Intensity $\mathrm{I}_{\mathrm{A}}$.

\subsection{Damage identification}

Local damage quantification is possible from IDA Curve Sets using IMs of a real arbitrary seismic event. The East-West component of Accumoli Mw6.0 earthquake, occurred on August 24th 2016 (the first important shock of 2016 Central Italy seismic sequence), is used for this purpose. Fig. 6h shows horizontal acceleration waveform recorded in Amatrice station, the closest station to Accumoli earthquake's epicenter, scaled up with $\mathrm{SF}=2$.

Taking advantage of IDA Curve Sets depicted in Fig. 7, IMs of Accumoli earthquake ( $\mathrm{SF}=2$ ) are used to identify the damage in terms of estimated ranges and mean values (calculated from corresponding mean curves) of dt. For this purpose, PGA, $\mathrm{S}_{\mathrm{a}}(\mathrm{T} 1), \mathrm{ASI}, \mathrm{S}_{\mathrm{v}}(\mathrm{T} 1), \mathrm{PGV}, \mathrm{I}_{\mathrm{C}}$ and $\mathrm{I}_{\mathrm{A}}$ are considered, obtaining an overall average estimation of ranges and mean values of tensile damage. Fig. 10 shows IDA-based estimated damage, averaged with respect to all the aforementioned IMs. It is clearly demonstrated that Part 7 is the most damaged, where mean dt reached about 0.35 (minimum and maximum equal to 0.2 and 0.5 , respectively). On the other hand, Parts 1 and 9 present the lowest values of tensile damage (maximum $\mathrm{dt} \leq 0.15$ ).

In addition, for comparison purposes, tensile damage obtained from the non-linear dynamic analysis carried out with Accumoli earthquake is also reported in the plot of Fig. 10, namely Actual Damage. There is a good consistency between the latter and IDA-based Estimated Damage. Values of $\mathrm{dt}$ of all the nine Parts, result within the corresponding IDA-based esti- 
(a)

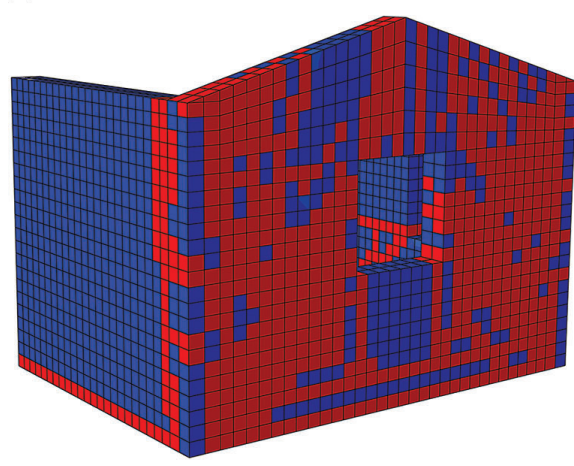

(c)

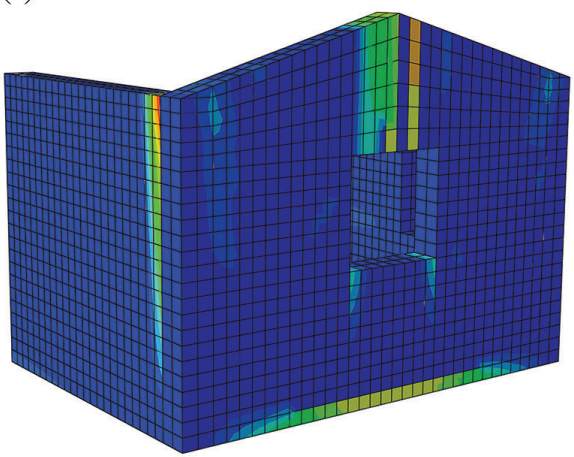

(b)

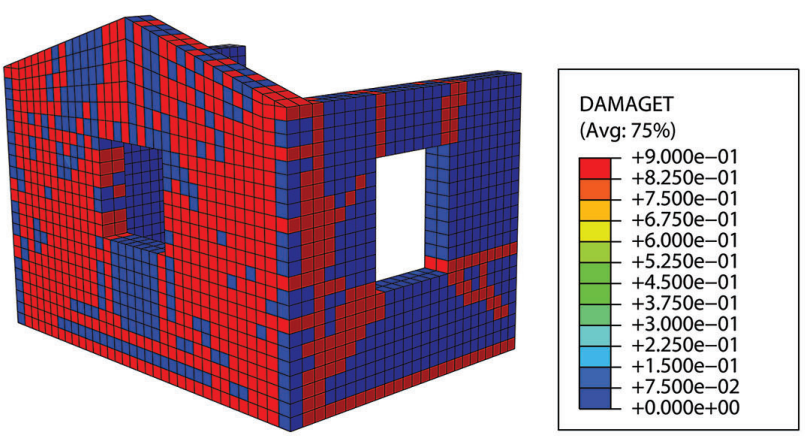

(d)

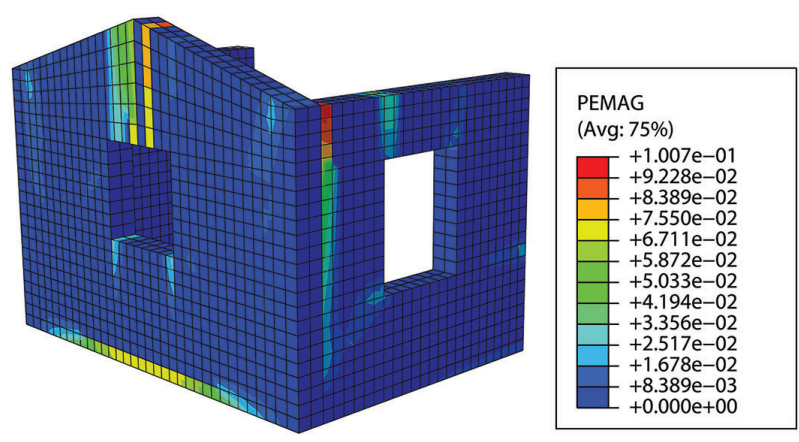

Figure 9: Contour plots of tensile damage ((a)-(b)) and plastic strain magnitude ((c)-(d)) obtained in the last step of the non-linear dynamic analysis performed with IT0806ya earthquake scaled at $\mathrm{SF}=3.5$.

mated mean ranges, meaning that IDA Curve Sets represent a valuable and reliable tool for earthquake-induced damage localization and quantification.

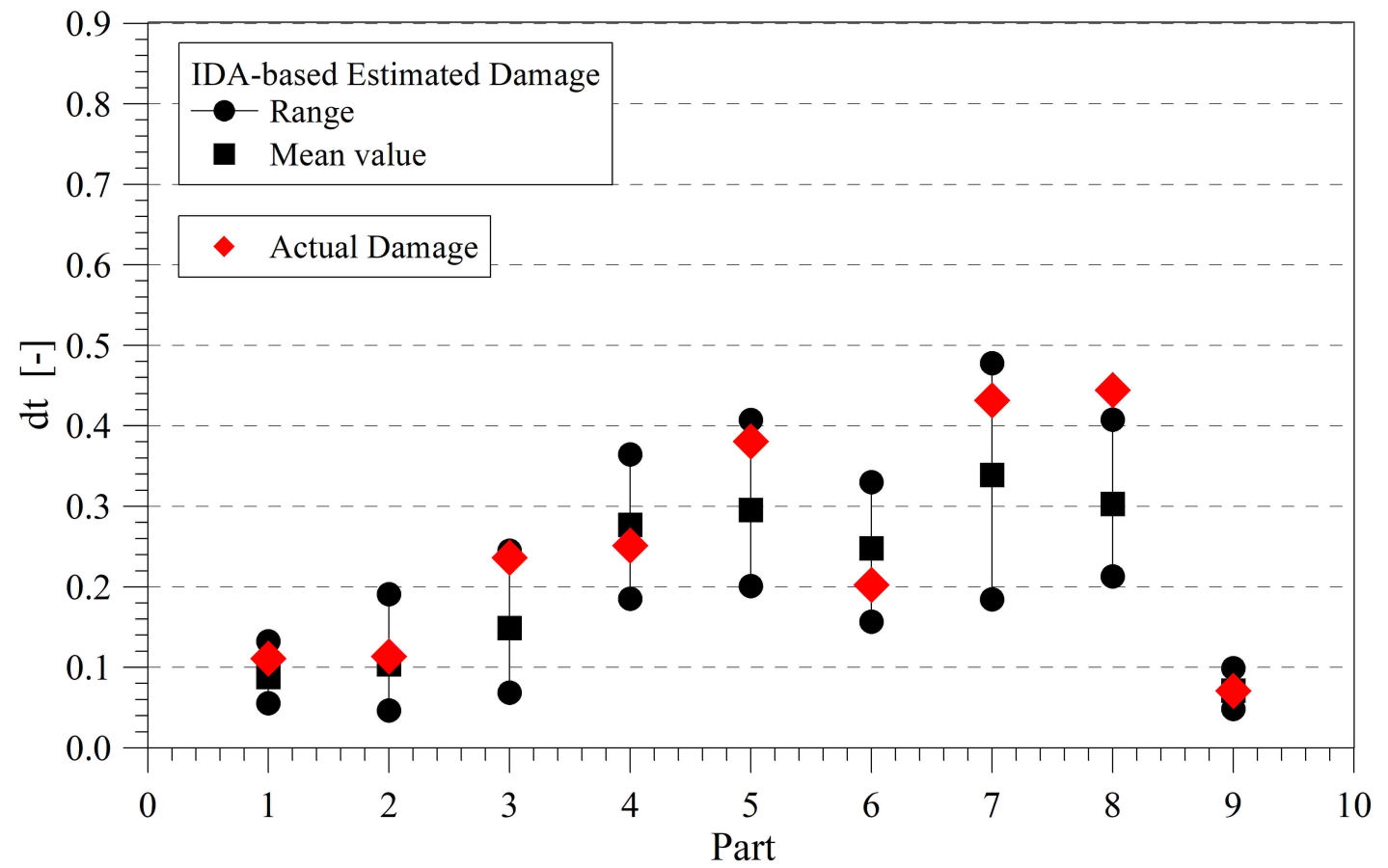

Figure 10: Tensile damage ranges and mean values obtained from IDA Curve Sets and corresponging mean curves, respectively, considering Accumoli's PGA, $\mathrm{S}_{\mathrm{a}}(\mathrm{T} 1)$, ASI, $\mathrm{S}_{\mathrm{v}}(\mathrm{T} 1), \mathrm{PGV}, \mathrm{I}_{\mathrm{C}}$ and $\mathrm{I}_{\mathrm{A}}$. 


\section{CONCLUSIONS}

The paper has presented an innovative methodology able to localize earthquake-induced damage. It is based on Incremental Dynamic Analysis carried out from a numerical model and using data recorded during seismic events. The crucial aspect relies on the fact that IDA Curve Sets have been built not considering the whole structure but referring to some portions of the latter. Thus, local damage parameters (DMs) have been related to selected seismic or response intensity measures (IMs), and this relationship has been used to locally identify the damage in such portions through earthquake's intensity.

The proposed methodology is validated through the FE model of a reduced-scale masonry structure, a.k.a. the Brick House, which represents a notable scientific experimental benchmark, object of previous studies by several authors.

The main results achieved within this work are summarized below.

- Concerning the construction and validation of the 3D numerical model based on the shaking table experimental results, full consistency between numerically predicted and experimental response accelerations has been achieved, together with a good agreement between numerical damage pattern and mock-up collapse machanism.

- Research results about acceleration-related IMs and their statistical correlation study considering one hundred seismic records have been presented. Among them, only the most suitable and meaningful ones have been chosen for IDA purposes.

- Nine IDA Curve Sets, one for every Part of the FE model, have been presented considering tensile damage and plastic strain magnitude as DMs versus Acceleration Spectrum Intensity and Arias Intensity as IMs, respectively.

- Damage has been sequentially localized mostly in Parts 7, 5 and 8 of the façade wall and Part 4 of the sidewall with opening, as indicated from DMs plots.

- IDA results, considering both dt and PEMAG, have presented a good agreement with damage pattern, crack formation and collapse mechanism experimentally observed during the shaking table tests.

- Earthquake-induced damage localization and quantification has been achieved with a good level of approximation in the case of a real seismic event, by means of IDA Curve Sets and corresponding mean curves, resulting the latter in a reliable tool for an arbitrary earthquake.

For the present case study, the results demonstrate that the proposed numerical IDA-based procedure is capable of correctly localizing earthquake-induced damages in different regions of the structure, as well as providing useful information for its quantification, with a certain level of confidence.

\section{REFERENCES}

[1] C.R. Farrar, K. Worden, An introduction to structural health monitoring. Philosophical Transactions of the Royal Society A, 365, 303-315, 2007.

[2] A. Alvandi, C. Cremona, Assessment of vibration-based damage identification techniques. Journal of Sound and Vibration, 292, 179-202, 2006. 
[3] A. Brencich, D. Sabia, Experimental identification of a multi-span masonry bridge: the Tanaro Bridge. Construction and Building Materials, 22, 2087-2099, 2008.

[4] L.F. Ramos, L. Marques, P.B. Lourenço, G. DeRoeck, A. Campos-Costa, J. Roque, Monitoring historical masonry structures with operational modal analysis: two case studies. Mechanical Systems and Signal Processing, 24(5), 1291-1305, 2010.

[5] M.G. Masciotta, L.F. Ramos, P.B. Lourenço, The importance of structural monitoring as a diagnosis and control tool in the restoration process of heritage structures: A case study in Portugal. Journal of Cultural Heritage, 27, 36-47, 2017.

[6] F. Ubertini, N. Cavalagli, A. Kita, G. Comanducci, Assessment of a monumental masonry bell-tower after 2016 Central Italy seismic sequence by long-term SHM. Bulletin of Earthquake Engineering, 16, 775-801, 2018.

[7] D. Vamvatsikos, C.A. Cornell, Incremental Dynamic Analysis. Earthquake Engineering and Structural Dynamics, 31, 491-514, 2002.

[8] Italian Ministry of Infrastructures and Transport, Approvazione delle nuove Norme Tecniche per le Costruzioni, Decreto Ministeriale 17 gennaio 2018. Supplemento Ordinario alla Gazzetta Ufficiale, 8(42), 2018.

[9] P.B. Lourenço, N. Mendes, A.A. Costa, A. Campos Costa, Methods and Challenges on the Out-of-Plane Assessment of Existing Masonry Buildings. International Journal of Architectural Heritage, 11, 2017.

[10] P.X. Candeias, A. Campos Costa, N. Mendes, A.A. Costa, P.B. Lourenço, Experimental Assessment of the Out-of-Plane Performance of Masonry Buildings Through Shaking Table Tests. International Journal of Architectural Heritage, 11, 31-58, 2017.

[11] Simulia, corp., Abaqus Analysis User's Manual. Volume III: Materials. Dessault Systèmes, USA, 2010.

[12] M. Valente, G. Milani, Seismic assessment of historical masonry towers by means of simplified approaches and standard (FEM). Construction and Building Materials, 108, 74-104, 2016.

[13] J. Lubliner, J. Olive, S. Oller, E. Onate, A Plastic-Damage Model for Concrete. International Journal of Solids and Structures, 25, 229-326, 1989.

[14] J. Lee, G.L. Fenves, Plastic-Damage Model for Cyclic Loading of Concrete Structures. Journal of Engineering Mechanics, 124, 892-900, 1989.

[15] M. Gams, A. Anžlin, M. Kramar, Simulation of Shake Table Tests on Out-of-Plane Masonry Buildings. Part (III): Two-Step FEM Approach. International Journal of Architectural Heritage, 11, 94-102, 2017.

[16] R. Riddell, On Ground Motion Intensity Indices. Earthquake Spectra, 23(1), 147-173, 2007. 
[17] O.W. Nuttli, The relation of sustained maximum ground acceleration and velocity to earthquake intensity and magnitude. Miscellaneous Paper S-71-1, Report 16, U.S. Army Corps of Engineers, Waterways Experiment Station, Vicksburg, Mississippi, 1979.

[18] J.W. Reed, N. Anderson, N.C. Chokshi, R.P. Kennedy, W.J. Metevia, D.K. Ostrom, J.D. Stevenson, A criterion for determining exceedance of the operating basis earthquake: Final report. EPRI Report NP-5930, Electric Power Research Institute, Palo Alto, California, USA, , 1988.

[19] R. Riddell, J.E. Garcia, Hysteretic energy spectrum and damage control. Earthquake Engineering and Structural Dynamics, 30(12), 1791-1816, 2001.

[20] Y-J. Park, A.H.-S. Ang, Y.K. Wen, Seismic damage analysis of reinforced concrete buildings. Journal of Structural Engineering, 111(4), 740—757, 1985.

[21] A. Arias, A measure of earthquake intensity. Seismic design of nuclear power plants (ed. R.J. Hansen), MIT Press, Cambridge, Massachusetts, , 438-483, 1970.

[22] S.K. Sarma, K.S. Yang, An evaluation of strong motion records and a new parameter A95. Earthquake Engineering and Structural Dynamics, 15(1), 119-132, 1987.

[23] R. Araya, G.R. Saragoni, Earthquake Accelerogram Destructiveness Potential Factor. 8th World Conference on Earthquake Engineering, San Francisco. U.S.A. 1984.

[24] S. Muin, K.M. Mosalam, Cumulative Absolute Velocity as a Local Damage Indicator of Instrumented Structures. Earthquake Spectra, 33(2), 641-664, 2017.

[25] S.L. Kramer, Geotechnical earthquake engineering, 1st Edition. Upper Saddle River, N.J., Prentice Hall, 1996.

[26] N. Shome, C.A. Cornell, P. Bazzurro, J.E. Carballo, Earthquakes, Records, and Nonlinear Responses. Earthquake Spectra, 14(3), 469-500, 1998.

[27] S.S. Mehanny, P.P Cordova, Development of a two-parameter seismic intensity measure and probabilistic design procedure. Journal of Engineering and Applied Science, 51(2), 233-252, 2004.

[28] M. Bianchini, P.P. Diotallevi, J.W. Baker, Prediction of inelastic structural response using an average of spectral accelerations. 10th international conference on structural safety and reliability (ICOSSAR09), Osaka, Japan, September 13-17, 2009.

[29] J.L. Von Thun, L.H. Rochim, G.A. Scott, J.A. Wilson, Earthquake ground motions for design and analysis of dams. Earthquake Engineering and Soil Dynamics II - Recent Advances in Ground-Motion Evaluation, Geotechnical Special Publication, 20, 463-481, Park City, Utah, United States, June 27th-30th, 1988.

[30] J.M. Nau, W. J. Hall, Scaling methods for earthquake response spectra. Journal of Structural Engineering, 110(7), 1533-1548, 1984.

[31] L. Luzi, F. Pacor, R. Puglia, Italian Accelerometric Archive v 2.3. Istituto Nazionale di Geofisica e Vulcanologia, Dipartimento della Protezione Civile Nazionale, 2017. 
[32] F. Pacor, R. Paolucci, L. Luzi, F. Sabetta, A. Spinelli, A. Gorini, M. Nicoletti, S. Marcucci, L. Filippi, M. Dolce, Overview of the Italian strong motion database ITACA 1.0. Bulletin of Earthquake Engineering, 9, 1723-1739, 2011.

[33] L. Al-Atik, N.A. Abrahamson, An improved method for nonstationary spectral matching. Earthquake Spectra, 26, 601-617, 2010.

[34] D.N. Grant, R. Diaferia, Assessing adequacy of spectrum-matched ground motions for response history analysis. Earthquake Engineering and Structural Dynamics, 42, 12651280, 2012.

[35] NZS 1170.5:2004, Structural Design Actions Part 5: Earthquake actions-New Zealand. Standards New Zealand.

[36] NZS 1170.5 Supp 1:2004, Structural Design Actions Part 5: Earthquake actions-New Zealand-Commentary. Standards New Zealand.

[37] M.C. Gerstenberger, G.H. McVerry, D.A. Rhoades, M.W. Stirling, K.R. Berryman, T.H. Webb, 2011 Update of the Z-factor for Christchurch considering earthquake clustering following the Darfield earthquake. Lower Hutt, N.Z.: GNS Science. GNS Science report 2011/29, 29, 20p, 2011.

[38] Seismosoft [2018], SeismoMatch - A computer program for spectrum matching of earthquake records. Available from URL: www.seismosoft.com 